\title{
Emission thermophotometry: principles, instrumentation and applications
}

\author{
W. W. Wendlandt \\ Department of Chemistry, University of Houston, Houston, Texas 77204-5641 (U.S.A.)
}

\begin{abstract}
The technique of emission thermophotometry (ETP) is discussed briefly from the viewpoints of general principles, instrumentation, and application to various chemical substances. ETP detects and records the light emitted by a chemical reaction that is thermally initiated, usually in the temperature range of $200^{\circ}-300^{\circ} \mathrm{C}$. Perhaps the most important application of ETP is in the thermal degradation of polymers, although it can be used to study explosives and propellants as well.
\end{abstract}

\section{INTRODUCTION}

The light emission (LE) of polymers, organic compounds, coordination compounds, and many other substances has been of interest in this laboratory since 1974. For lack of a better name, the term "light emission" (LE) was employed to describe this technique although Ashby [1] called it "oxyluminescence" in his applications to polymers. Barker et .al. [2] used the term "thermoluminescence" while David [3] called it "photothermalanalysis" (PTA). Because of the broader application of this technique to substances such as coordination compounds, this laboratory has preferred the name "light emission". From the viewpoint of the nomenclature proposed by the International Confederation for Thermal Analysis (ICTA) [4], a more appropriate name is emission thermophotometry (ETP) since the technique measures the emission of light from a sample as it is heated in an air or oxygen atmosphere at a controlled temperature program (i.e., increasing heating rate). ICTA defines the thermal analysis technique of "thermophotometry" as the measurement of total light; the adjective "emission" would make the name more definitive.

As another thermal analysis technique [5], ETP is, of course, dependent on instrumentation and sample variables such as furnace heating rate, sample mass, sample geometry (shape or form), type of furnace atmosphere, geometry of the photometric detection devices, etc. However, it is a relatively simple technique with uncomplicated instrument components of great reliability coupled with simple procedural parameters. the most complex component of the ETP apparatus is the computer data gathering and manipulation system which uses a commercially available microcomputer.

The technique of ETP will be discussed here according to : (a) Principles; (b) Instrumentation; and (c) Application to various chemical systems, both organic and inorganic. Most of the discussion presented will be concerned with work done in the author's laboratory; lack of space prevents a more comprehensive review of all of the work in this field, especially in polymeric systems [19].

\section{PRINCIPLES OF EMISSION THERMOPHOTOMETRY (ETP)}

Although the detection of light emission from a chemical reaction excited by thermal means has been known for many years, the first modern application of this phenomenon was by Ashby in 1961 [1]. He observed that by heating polypropylene in an oxygen atmosphere in the temperature range from $150^{\circ}$ to $300^{\circ} \mathrm{C}$, a low-level emission of light was detected. Since the light emission (LE) could only be observed in the presence of oxygen, he coined the term "oxyluminescence" to describe this process. The intensity of the LE was proportional to the concentration of oxygen in contact with the polymer surface and that the presence of polymer stabilizers decreased the intensity of the light. Thus a new tool was discovered which would provide invaluable insight into the study of the oxidative degradation of polymers as well as to elucidate the effects of stabilizers on the polymer oxidation process. This LE process is not the same as thermoluminescence (TL) which McKeever 
[6] defines as the emission of light from an insulator or semiconductor when it is heated or the thermally stimulated emission of light following the previous absorption of energy from radiation. To exhibit TL, the material must be an insulator or semiconductor, it must have at one time absorbed energy by exposure to radiation, and lastly, the light emission is triggered by heating the material.

The substances studied by ETP can be simple organic molecules, polymeric substances, biological substances, high energy organic molecules or salts, or coordination compounds containing vigorous oxidizing and reducing groups. The LE process is triggered by heating, usually at modest programmed furnace heating rates of $10-20^{\circ} \mathrm{C} \mathrm{min-1.} \mathrm{An} \mathrm{oxygen} \mathrm{atmosphere} \mathrm{may} \mathrm{be} \mathrm{necessary} \mathrm{for}$ LE but is not required for substances containing oxidizing and reducing groups. A criteria that is different here from the original work of Ashby [1] is the non-isothermal heating of the sample. Early oxyluminescence measurements were made in the isothermal mode which was used to great advantage in polymer degradation investigations.

In essence then, the substances studied in our investigations were subjected to a non-isothermal heating mode, at which time low-level (in most cases) light emission was detected by the technique of emission thermophotometry. The sample could undergo a phase charge such as fusion, thermal decomposition, oxidative degradation, or participate in a vigorous internal oxidation-reduction process (redox reaction). During any or all of these steps, light emission may be observed from the sample. This light is detected by a photomultiplier or other photometric sensor, converted to an electrical signal which is then stored and manipulated by a computer data station. Plots of these data versus sample temperature reveals, in many cases, curves that are characteristic of the substances being investigated. As with many other thermal analysis techniques, the ETP curves may be used to qualitatively identify the sample or to determine the initial temperature at which a specific type of reaction occurs.

\section{INSTRUMENTATION}

The instrumentation used to follow the LE process is relatively simple. It generally consists of a light detection apparatus containing a sensitive photomultiplier tube and photometer; a furnace and temperature controller or programmer; an enclosed chamber surrounding the sample which is capable of a controlled static or dynamic atmosphere of oxygen or other gases; and a recording system. The output from the photometer is plotted vs. time (isothermal mode) or temperature (nonisothermal mode). Most of the early studies used the isothermal mode but more recent investigations employed the non-isothermal mode. Many of the early isothermal studies were carried out at a temperature of $150^{\circ} \mathrm{C}$ both the non-isothermal mode has been used to study polymers up to a maximum temperature of $400^{\circ} \mathrm{C}$. This is usually the upper temperature limit because of radiation effects which mask the OL emission. However, Wendlandt [7] used a data center recorder which permitted the deletion of the background radiation of the curves giving only the OL vs. the temperature curves. A system for low-temperature measurements to $-196^{\circ} \mathrm{C}$ has also been reported Kaimin and Galeis [8].

Oxyluminescence measurements at low pressures have been made by Barker et al. [2] who also analyzed the gaseous and condensation extractable pyrolysis products of the polymer by gas chromatography and mass spectrometry. Simultaneous LE and DTA data were obtained by David [3] using a commercial DTA apparatus and a photometric detector. Wynne and Wendlandt $[9,10]$ also made LE-DSC/DTA measurements using commercial DSC/DTA instruments. Light emission measurements coupled with smoke evolution detection and TG were made by Johnson and Chiu [11]. Instruments for detection of very low-level LE of polymers using photon-counting techniques have been described by George $[12,13]$ and others $[14,15]$.

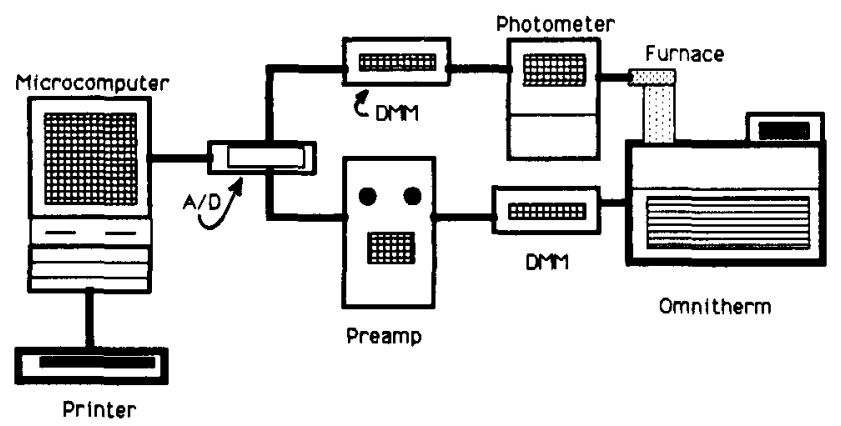

Fig. 1. Schematic diagram of the emission thermophotometry apparatus. 


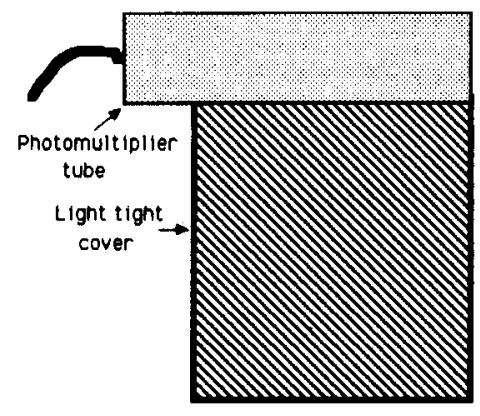

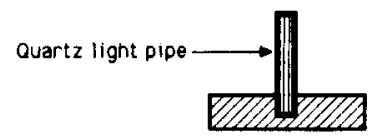

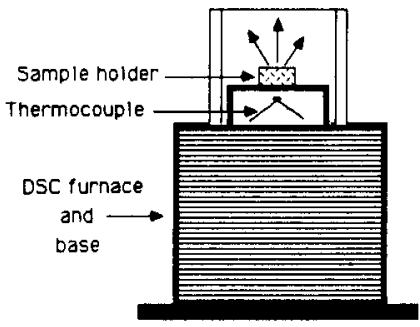

Fig. 2. Schematic diagram of the furnace and sample holder of the ETP apparatus.

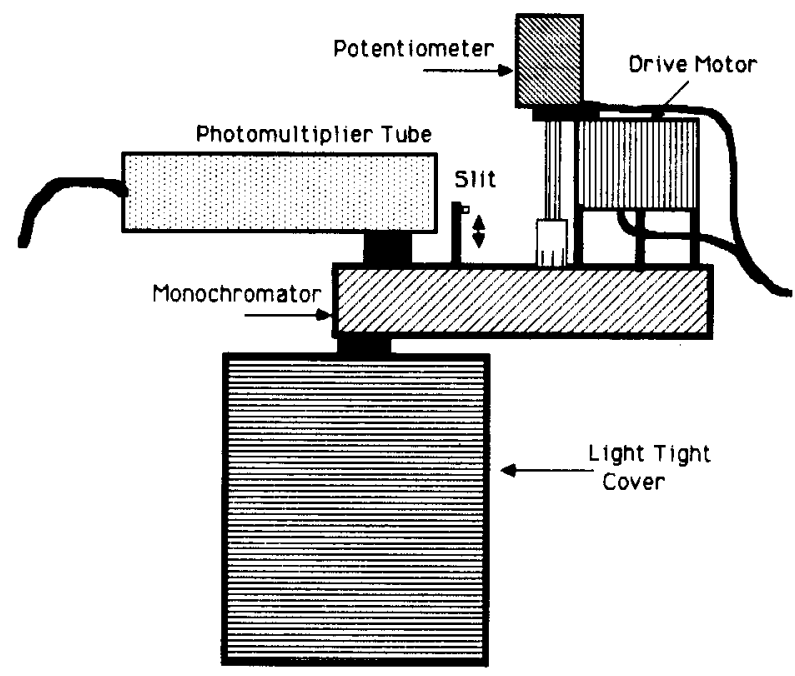

Fig. 3. Schematic diagram of attachment of monochromator to ETP system.

Several instruments for ETP have been developed in this laboratory, the first of which was built in 1974 [10]. It used the furnace contained in a commercial DSC/DTA instrument coupled to a photoncounter. Another apparatus permitted the LE of a sample to be obtained at reduced pressures from 10-750 torr [16]. This apparatus was later modified to permit simultaneous LE-DTA measurements [17]. The latest version of the LE system is shown in Figs. 1 and 2 [18]. Without going into specific component details, the system consisted basically of a commercial DSC apparatus (Omnitherm Corp.); a photometer and PMT; a d.c. voltage pre-amplifier for the thermocouple signals; an A/D converter and scanner; and a data station consisting of a Apple IIe microcomputer, disk storage, and printer. The furnace and sample holder was constructed from a DuPont DSC cell. A schematic diagram of the furnace and sample holder is shown in Fig. 2. Light emitted from the sample was transmitted via the quartz light pipe to the PMT. Excellent temperature control of the furnace was maintained by the Omnitherm temperature programmer.

The spectral distribution of the emitted light for certain polymers has been measured in a crude manner by the use of wavelength filters. Ashby [2] found that the PMT anode current was attenuated by about $50 \%$ by interposing a filter that absorbed light of wavelengths shorter than 420 $\mathrm{nm}$ between the polymer and the PMT. No current could be detected if a filter was interposed that absorbed all wavelengths shorter than $515 \mathrm{~nm}$. It was concluded that in oxyluminescence, the light emission by polymers in air or oxygen, $50 \%$ of the light emission had wavelengths between 420 and $515 \mathrm{~nm}$ and $50 \%$ between 300 and $420 \mathrm{~nm}$. Barker et al. [3] also employed filters to determine the spectral distribution of light emission by certain polymers and found that the spectrum consisted of a broad peak from 400 to $610 \mathrm{~nm}$ with a maximum at $540 \mathrm{~nm}$, and a shoulder peak at $475 \mathrm{~nm}$. Using wavelength filters, de Kock and Hol [4] obtained the light emssion spectrum of dicumyl peroxide in polypropylene. The spectrum extended from 360 to about $500 \mathrm{~nm}$ with a peak maximum at $420 \mathrm{~nm}$. It was very similar to the phosphorescence spectrum of acetophenone dissolved in poly(methylmethacrylate).

In order to measure the light emission wavelength distribution of poly(ethylene oxide), a strong emitter, the emitted light was passed through a grating monochromator which could be scanned mechanically over the wavelength range of $400-700 \mathrm{~nm}$. due to the low-level light intensities involved and the wide monochromator slit widths employed, the spectrum obtained was only approximate.

The apparatus used to measure the spectral distribution of the emitted light for certain polymers is shown in Fig. 3 [23]. A small, motor driven, grating monochromator scanned the emitted light from the sample. A retransmitting potentiometer, connected to the wavelength shaft of the monochromator, gave a voltage output that was proportional to the wavelength." 


\section{APPLICATIONS}

As expected, most of the light emission (i.e., oxyluminescence) studies have ben made on polymeric substances. Many of these investigations were in the isothermal mode of temperature programming; only a few studies (mostly from this laboratory) were concerned with the non-isothermal mode (as in conventional thermal analysis). A list of polymers that have been studied by OL or ETP has been published [19]. Accordingly, the applications described briefly here include: (1) Polymeric substances; (2) Organic and biological substances; and (3) Inorganic substances, including coordination compounds.

\section{Polymeric substances}

In the isothermal mode, the effect of atmosphere and stabilizer concentration permitted evaluation of the kinetics of the $\mathrm{OL}$ process. The $\mathrm{E}_{\mathrm{a}}$ values for a number of polymer (mostly hydrocarbons) have been tabulated [19]. Ashby [1] had previously pointed out that the presence of antioxidants (stabilizers) resulted in a change in the OL. Using polypropylene containing a 1:1 mixture of the stabilizer, 4,4'-thiobis(6-tert-butyl-o-cresol) with dilaurylthiopropionate, the OL intensity was greatly reduced for an initial time interval and the extent of this reduction was determined by the concentration of the stabilizer. When the stabilizer concentration was depleted, the OL returned to its original intensity. This suggested that the intensity of OL is reduced as the rate of oxidation was reduced by the stabilizer. A rapid method for determination of the concentration of the stabilizer in the polymer was also developed.

Schard and Russell [20] studied the OL change for polypropylene containing varying amounts of the stabilizer, 4,4'-thiobis(3-methyl-6-tert-butylphenol). the OL was delayed for a short period of time after admission of oxygen to the steam to an extent depending on the stabilizer concentration. The rate of rise in the OL emission curve appeared to vary inversely as a function of stabilizer concentration. Preliminary studies showed that the effect of stabilizer upon the OL of polyethylene was quite different from that in polyethylene. The time elapsed to reach maximum intensity of OL was of little value in the former studies since, with $0.1 \%$ of stabilizer present, the maximum intensity was attained almost instantly.

Collins and Wendlandt [21] used ETP to determine the stabilizer concentration in polyethylene. Four of the LE curves of polyethylene containing various amount of stabilizers are shown in Fig. 4.

Light emission occurs which produces a peak similar in shape to a DSC curve obtained over the same temperature interval, during the polymer degradation reaction. The initial deviation of the curve from the base line, $T i$, as well as the peak maxima temperature, $T p$, were both bound to be a function of the stabilizer content of the polymer; both $T i$ and $T p$ values increase with stabilizer content over the concentration range examined. both of these temperatures would be expected to be shifted to higher values since increases in antioxidant levels delay the chain reaction process. Changes in peak heights do not correspond to changes in antioxidant concentration so the photoemission intensity cannot be unequivocally linked to a particular physical process.

The LE curves (corrected for background thermal emission) for a number of cellulose derivatives are shown in Fig. 5 [22]. All of the curves are qualitative in nature but appear to be reproducible in the ETP apparatus. This is rather remarkable when it is considered that the polymer undergoes premelting, melting (in more cases) and thermal dissociation reactions, all resulting in surface area changes. The LE curves revealed that each curve appears to be unique for the particular cellulose derivative and hence can be used as a means of qualitative identification. LE peaks were found in the temperature range from $200^{\circ}$ to $400^{\circ} \mathrm{C}$, with most of the prominent peaks in the $200^{\circ}$ to $300^{\circ} \mathrm{C}$ range.

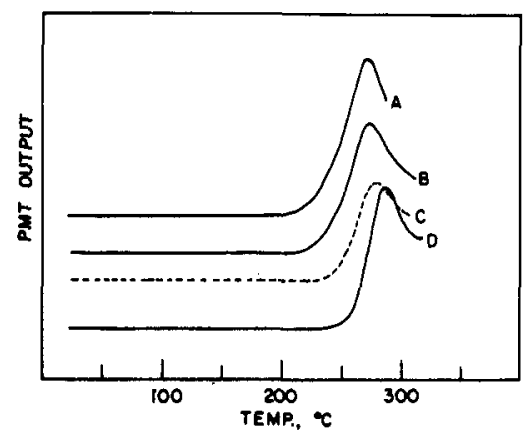

Fig. 4. Light emission curves for polyethylene with (A) no stabilizer, (B) $0.005 \%$, (C) $0.02 \%$, (D) $0.05 \%$ Irganox $1010^{\mathrm{TM}}$ in an oxygen atmosphere at a heating rate of $10^{\circ} \mathrm{C} / \mathrm{min}$ and a sample weight of $5 \pm 1 \mathrm{mg}$.

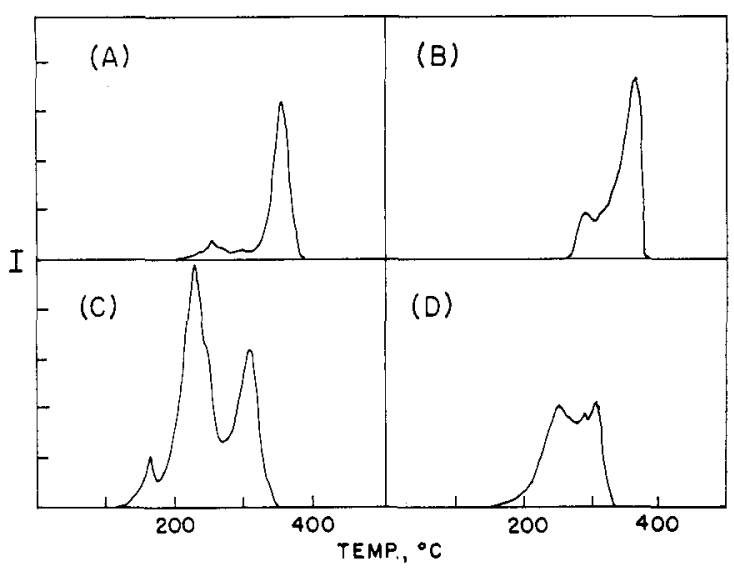

Fig. 5. Oxyluminescence of various cellulose derivatives. (A) Cellulose acetate; (B) cellulose propionate; (C) ethyl cellulose; (D) methyl cellulose. 


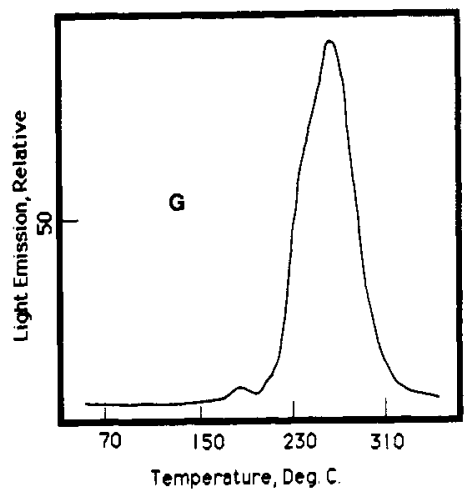

Fig. 6. (G) Nylon 12.

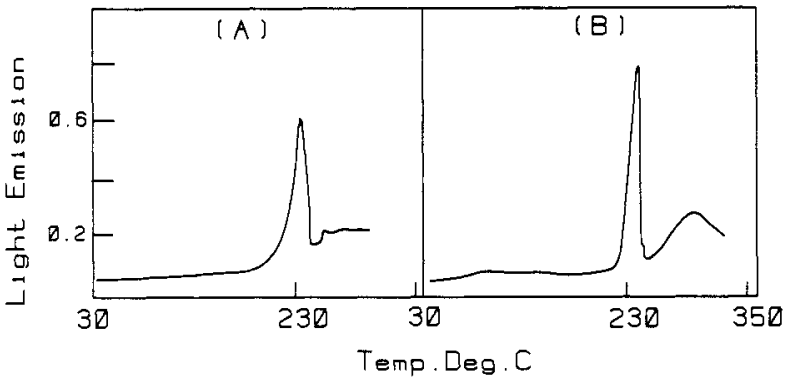

Fig. 7. ETP curves of amino acids: (A) L-phenylalanine; (B) L(+) glutamine.

The light emission, as detected by ETP, of some selected nylon polymers has been reported by Wendlandt [24]. As found in an earlier OL investigation [25], most of the LE curves consisted of a single peak (except nylon 6/10) in the temperature range $200-300^{\circ} \mathrm{C}$. A representative of ETP curve for nỳlon 12 is illustrated in Fig. 6.

Each ETP curve is uniquely different, in reference to peak shape and peak maxima temperature. Nylon $6,6 / 6$ and $6 / 10$ all had shoulder peaks on the low temperature side of the main curve peak. The curve peak maximum for nylon $6 / 9$ is at about the same temperature, $220-230^{\circ} \mathrm{C}$, as the shoulder peak for nylon 6/10. The nylon 11 and 12 ETP curves were of the same general shape except that the peak maximum for the former is $240^{\circ} \mathrm{C}$ versus about $260^{\circ} \mathrm{C}$ for the latter. The highest temperature curve peak maximum, $350^{\circ} \mathrm{C}$, was found for nylon $6 / \mathrm{T}$ although there could have been one observed for nylon $6 / 9$ had the temperature axis been extended past $400^{\circ} \mathrm{C}$. Except for nylon 11 and 12 , it is not possible to correlate the ETP curve with structural parameters of the polymers because the curves are so dissimilar.

The origin of the light emission process has been reviewed by Wendlandt [19], Reich and Stivala [26], and others [27]. Although a mechanism is not known for the nylon polymers, for many hydrocarbon polymers the oxidation steps involved in molecular oxygen are [27] as follows.

(1) Initiation

$\mathrm{O}_{2}$

$\mathrm{PH} \rightarrow \mathrm{PO}_{2}$

$\mathrm{POOH} \rightarrow \mathrm{PO}_{2}$.

where $\mathrm{PH}=$ polymer; $\mathrm{H}=$ active hydrogen;

$\mathrm{PO}_{2} \cdot$ = peroxy radical (free radical).

(3) Termination

$\mathrm{P}_{2} \cdot \mathrm{PO}_{2} \cdot$

$\mathrm{PO}_{2}+\mathrm{P} \rightarrow$ non-radical products

$\mathrm{P} \cdot+\mathrm{P} \cdot$
(2) Propagation

$$
\begin{aligned}
& \mathrm{PO}_{2}+\mathrm{PH} \rightarrow \mathrm{POOH}+\mathrm{P} \cdot \\
& \mathrm{PO}_{2}+{ }^{\prime} \mathrm{C}=\mathrm{C}^{\prime} \rightarrow \mathrm{POO}-\mathrm{C}_{1}-\mathrm{C}^{\prime} \cdot(\mathrm{P} \cdot) \\
& \mathrm{P}+\mathrm{O}_{2} \rightarrow \mathrm{PO}_{2} \cdot \\
& \text { where } \mathrm{P}=\text { polymer radical. }
\end{aligned}
$$

The light emission from the polymer is thought to originate during the termination step [5], or:

$\mathrm{PO}_{2} \rightarrow$ products* $+\mathrm{O}_{2}$

products* $\rightarrow$ products

The products* may be an electronically excited ketone in which a transition of the type $n \rightarrow \pi$ can give rise to phosphorescence. It has been found that the maximum luminosity of the emitted light was related to the ability of the polymer to absorb oxygen and that it should be able to estimate the light emission from oxygen uptake [28].

\section{Organic and biological substances}

Strangely enough, Wendlandt [29] found that selected L-amino acids exhibited light emission in the temperature range of $200-350^{\circ} \mathrm{C}$. Although the light emission peaks in these curves appeared in the same general temperature range as those for various polymers the light-producing mechanism must certainly be different.

The EPT curves for L-phenylalanine and L (+) glutamine are shown in Fig. 7. 
Although it is beyond the scope of this review to discuss their thermal decomposition reactions, phenylalanine has been shown to exhibit a thermal decomposition curve that required a minimum of three Gaussian curves to resolve. This suggests that three steps are involved in the pyrolysis process in nitrogen. Since an oxygen atmosphere was used here, the decomposition reactions are no doubt completely different. However, the curve indicates multiple peaks suggesting at least two reactions. According to Hung [30], this amino acid dissociates (in $\mathrm{N}_{2}$ ) as shown in Scheme 1. The first step of the reaction has $E_{\mathrm{a}}=210 \mathrm{~kJ}$ mol-1; the second stage has $E_{\mathrm{a}}=69.9 \mathrm{~kJ} \mathrm{~mol}^{-1}$; and the third stage has $E_{\mathrm{a}}=12 \mathrm{~kJ} \mathrm{~mol}^{-1}$.

\section{Scheme 1}

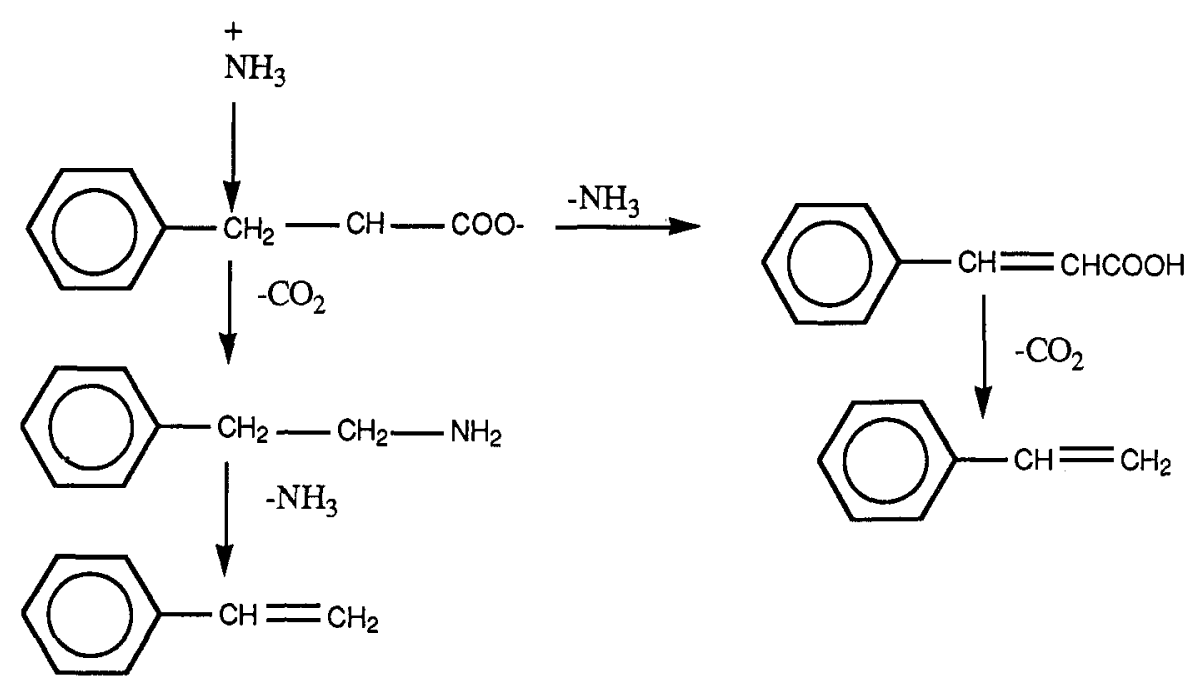

The thermal decomposition of the amino acids, which in many cases consisted of multiple reactions, may involve the formation of peroxy radicals as oxidation products. The residues examined after the pyrolysis runs were all solid, black, carbonaceous, voluminous masses. The possibility of "glowing" ignition of this residue is ruled out by the low temperature range (too low for ignition) and also the low level of the light emission. The light emission observed for the amino acids is no doubt due to the presence of certain pyrolysis products formed in an oxygen atmosphere. However, due to the limited data presented here, it is not possible to explain the exact origin of these light emission processes. The ETP curves may be used, in a limited manner, for the qualitative identification of the amino acids. Additional studies may elucidate the origin of the light emission reactions.

Using ETP, Wendlandt [31] found that certain guanidinium salts,<smiles>CCNC(=N)NCC</smiles>

exhibited LE during their thermal dissociation reactions. The origin of this light emission was due to an internal oxidation-reduction process since it only occurred with salts containing oxidizing anions. Typical ETP curves of guanidine thiocyanate and chromate are shown in Fig. 8.

Three types of LE behavior were noted for this compounds: (a) narrow band light emission similar to that observed for coordination compounds; (b) ignition of the compound; and (c) weak, broad LE spread out over a wide temperature range. Guanidine sulfate and chromate exhibit type (a) LE. Like coordination compounds containing reducing $\left(\mathrm{NH}_{3}\right.$, ethylenediamine, etc.) and oxidizing $\left(\mathrm{NO}_{3}{ }^{-}\right.$, $\mathrm{ClO}_{4}^{-}, \mathrm{SO}_{4}^{2-}$ etc.) groups, guanidine sulfate and chromate possess reducing and oxidizing ions. Hence, the LE curves are similar to those observed for coordination compounds. The highly exothermic nature of the decomposition reaction is clearly shown by the LE curve of guanidine chromate in which there is a rapid temperature excursion that distorts the temperature axis of the curve. This behavior has previously been seen on the LE-DTA curves of certain coordination compounds. Guanidine thiocyanate exhibits type (b) LE in which the compound or its decomposition products ignite during the reaction. Since the reaction was carried out in an oxygen atmosphere, this behavior is probably expected. Guanidine carbonate and chloride exhibit little if any $\mathrm{LE}$, as expected. 


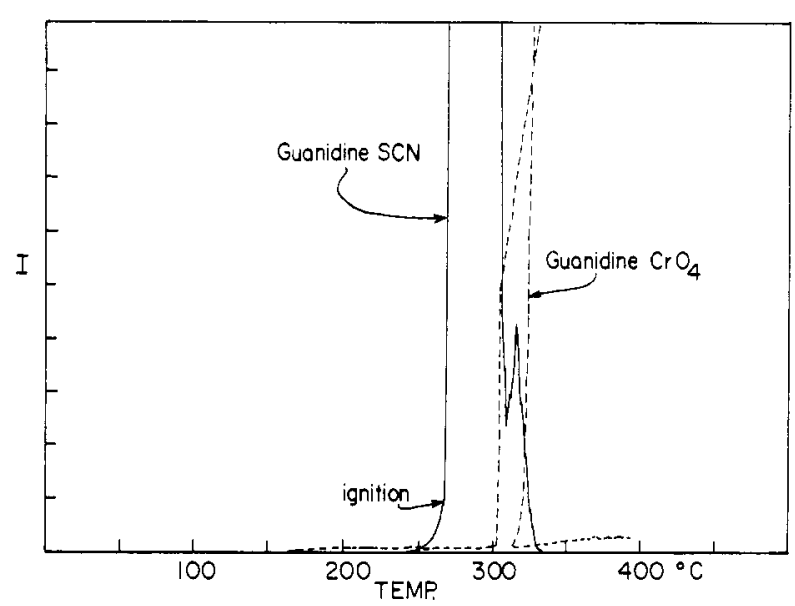

Fig. 8. LE curves of guanidine thiocyanate and chromate.

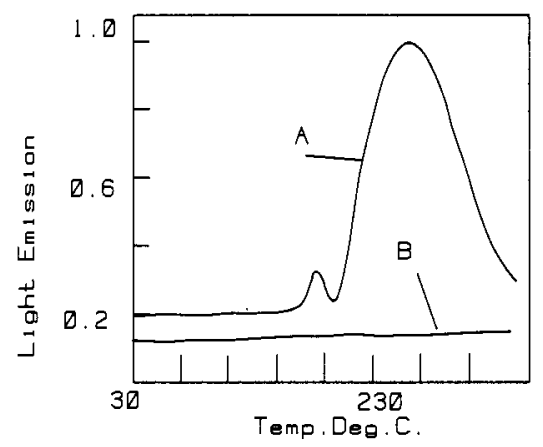

Fig. 9. ETP curves of $\mathrm{NH}_{3} \cdot \mathrm{BH}_{3}$ in (A) oxygen and $(B)$ nitrogen atmospheres.

\section{Inorganic compounds}

Numerous inorganic compounds have been shown to exhibit light emission. Most of these compounds certain vigorous oxidizing and reducing groups and thus exhibit a highly exothermic thermal dissociation reaction. Examples of such compounds include hydrazinium and ammonium salts [32], and numerous coordination compounds [33,34]. Surprisingly, ammonia-borane, $\mathrm{NH}_{3} \mathrm{BH}_{3}$, also exhibits light emission properties although it does not contain an oxidizing group $[35,36]$.

The ETP curves of $\mathrm{NH}_{3} \cdot \mathrm{BH}_{3}$ in oxygen and nitrogen atmospheres are illustrated in Fig. 9. It is evident from the curves that essentially no light is detected with a nitrogen atmosphere over the sample (Fig. 1B) whereas copious light emission results when an oxygen atmosphere is present (Fig. 1A). The fact that light emission first appears at $180-190^{\circ} \mathrm{C}$ suggests that it is not $\mathrm{NH}_{3} \cdot \mathrm{BH}_{3}$ itself, but rather one or more of its thermal decomposition products which is responsible for the light emission since $\mathrm{NH}_{3} \cdot \mathrm{BH}_{3}$ decomposition begins near $120^{\circ} \mathrm{C}$. It is believed that in the oxygen atmosphere an oxidation reaction of some decomposition product(s) occurs emitting the observed light.

Boranes, in general, have very exothermic heats of combustion and pentaborane, one of the likely decomposition products, can inflame spontaneously upon contact with oxygen (eqn. 1). Mixtures of $\mathrm{B}_{5} \mathrm{H}_{9}$ and $\mathrm{O}_{2}$ below the explosive ratio are reported to undergo a luminous reaction depositing a white solid on the container walls:

$$
2 \mathrm{~B}_{5} \mathrm{Hg}(\mathrm{g})+12 \mathrm{O}_{2}(\mathrm{~g}) \rightarrow 5 \mathrm{~B}_{2} \mathrm{O}_{3}(\mathrm{~s})+9 \mathrm{H}_{2} \mathrm{O}(\mathrm{g})
$$

Thus is seems reasonable to suppose that the observed thermal light emission from $\mathrm{NH}_{3} \cdot \mathrm{BH}_{3}$ has its origin in oxidation reaction(s) involving the $\mathrm{B}-\mathrm{H}$ bonds of one or more of its decomposition products.

In an investigation of fifty coordination compounds[34], sixteen exhibited LE under the experimental conditions employed. Of the cobalt(III) compounds studied, light emission during thermal dissociation was linked with the presence of carbon-containing ligands such as en, dien, trien, etc. Complexes that contained only ammonia ligands, such as $\left[\mathrm{Co}\left(\mathrm{NH}_{3}\right)_{6}\right]\left(\mathrm{NO}_{3}\right)_{3}$. $\mathrm{NH}_{4}\left[\mathrm{Co}\left(\mathrm{NH}_{3}\right)_{2} \mathrm{NO}_{2}\right.$ oxalate], [ $\left.\mathrm{Co}\left(\mathrm{NH}_{3}\right)_{4}\left(\mathrm{NO}_{3}\right)_{2}\right] \mathrm{NO}_{3}$, etc., did not exhibit light emission. Also, several nickel(II), rhodium(III), and platinum(II) compounds did not exhibit LE during their decomposition reactions, irrespective of the fact that they contained en or $\mathrm{NH}_{3}$ ligands. Using a more sensitive light detection system (DTA and LE) [35], it was found that LE did indeed occur in certain compounds although they did not contain carbon-containing reducing ligands.

Some typical LE curves of coordination compounds containing reducing and oxidizing ligands are shown in Fig. 10. Most of the LE curves were quite narrow, except for those compounds containing the dien ligand. The vigorous exothermic nature of these decomposition reactions were shown by supporting DTA and TG data. 


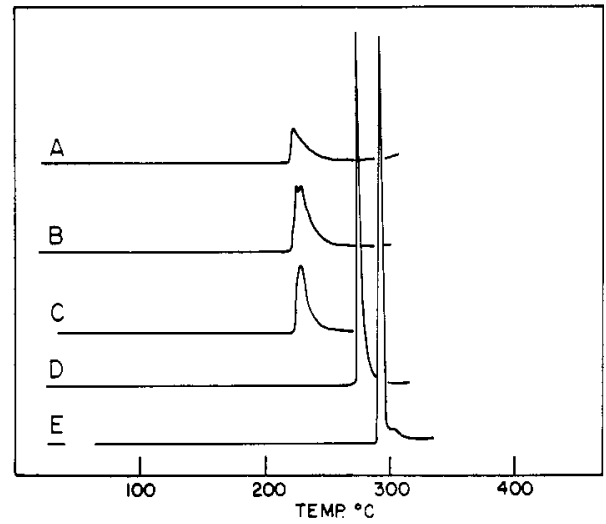

Figure 10. Light emission curves of some coordination compounds.
A, $\alpha$-cis $\left[\mathrm{Co}(\right.$ trien $\left.)\left(\mathrm{NO}_{2}\right)_{2}\right] \mathrm{Cl}$;
$\mathrm{B},\left[\mathrm{Co}(\operatorname{dien})\left(\mathrm{NO}_{3}\right)_{3}\right]$
$\mathrm{C},\left[\mathrm{Co}(\right.$ dien $\left.) \mathrm{NH}_{3}\left(\mathrm{NO}_{2}\right)_{2}\right] \mathrm{Cl}$;
$\mathrm{D}$, cis- $\left[\mathrm{Co}(\mathrm{en})_{2}\left(\mathrm{NO}_{2}\right)_{2}\right] \mathrm{NO}_{3}$;
$\mathrm{E},\left[\mathrm{CO}\left(\mathrm{NH}_{3}\right)_{4} \mathrm{en}\right]\left(\mathrm{NO}_{3}\right)_{3}$.

\section{CONCLUSION}

It is seen from the previous discussion that emission thermophotometry (ETP) can be used to study the thermal light emission of a wide variety of chemical substances. The technique appears to be most useful for studying the LE of polymers, where it can be used for thermal dissociation reaction mechanism investigations and stabilizer/inhibitor analysis. ETP appears also to be useful for investigation into reactions of substances containing vigorous oxidizing and reducing groups. This would include various explosives and propellants, selected coordination compounds, and so on.

Acknowledgement The financial support of this work by the Robert A. Welch Foundation of Houston, Texas, is gratefully acknowledged.

\section{REFERENCES}

1. G.E. Ashby, J. Polym. Sci, 50, 99 (1961).

2. R.E. Barker, J.H. Daane and P.M. Retzepis, J. Polym. Sci., Part A, 3, 2033 (1965).

3. D.J. David, Thermochim. Acta, 3, 277 (1972)

4. G. Lombardi, For Better Thermal Analysis ICTA, Rome, Italy, 1980.

5. W.W. Wendlandt, Thermal Analysis, 3rd. Ed., J. Wiley, New York, 1986.

6. S.W.S. McKeever, Thermoluminescence of Solids, Cambridge Univ. Press, 1 Cambridge, (1985).

7. W.W. Wendlandt, Thermochim. Acta, 68, 383 (1983).

8. I.F. Kaimin and Z.Z. Galeis, Vysokomol. Soedin, Serv. A, 9, 245 (1967).

9. A.M. Wynne and W.W. Wendlandt, Themochim., Acta 14, 61 (1976).

10. A.M. Wynne and W.W. Wendlandt, Thermochim., Acta 13, 393 (1975).

11. B.B. Johnson and J. Chiu, Thermochim. Acta, 50, 57 (1981).

12. G.A. George, in Developments in Polvmer Degradation, N. Grassie, Ed., Applied Science Publ., London, 1981.

13. G.A. George, Polym. Degrad. Stab., 1, 217 (1979).

14. G.D. Mendenhall, Agnew. Chem. Intl. Ed., 16, 225 (1977).

15. K. Naito and T.K. Kivei, J. Polym. Sci., Polym. Chem. Ed., 17, 2935 (1979).

16. W.W. Wendlandt, Thermochim. Acta, 35, 255 (1980).

17. W.W. Wendlandt, Thermochim. Acta, 39, 313 (1980).

18. W.W. Wendlandt, Thermochim. Acta, 99, 55 (1986).

19. W.W. Wendlandt, Thermochim. Acta, 72, 363 (1984).

20. M.P. Schard and C.A. Russell, J. Appl. Polym. Sci., 8, 997 (1964).

21. L.W. Collins and W.W. Wendlandt, Israel J. of Chem., 22, 233 (1982),

22. W.W. Wendlandt, Thermochim. Acta, 68, 387 (1983).

23. W.W. Wendlandt, Thermochim. Acta, 99, 61 (1984).

24. W.W. Wendlandt, Thermochim. Acta, 101, 89 (1986).

25. W.W. Wendlandt, Thermochim. Acta, 68, 383 (1983).

26. L. Reich and S.S. Stivala, Elements of Polvmer Degradation, McGraw-Hill, New York, 1971, p.5.

27. Y. Kamiya and E. Niki, in H.H.G. Jellinek (Ed.), Degradation and Stabilization of Polymers, Elsevier, Amsterdam, 1983, p. 337.

28. L. Reich and S.S. Stivala, J. Polym. Sci., Part A, 3, 4299 (1965).

29. W.W. Wendlandt, Thermochim. Acta, 114, 381 (1987).

30. G.W.C. Hung, Thermochim. Acta, 23 233, (1978).

31. W.W. Wendlandt, Thermochim. Acta, 70, 379, (1983)

32. W.W. Wendlandt and M. Kasper, Thermochim. Acta, 75, 245, (1984),

33. W.W. Wendlandt, Thermochim. Acta, 35, 247 (1980).

34. W.W. Wendlandt, Thermochim. Acta, 35, 313 (1980).

35. V.Sit, R.A. Geanangel and W.W. Wendlandt, Thermochim. Acta, 113, 379 (1987).

36. R.A. Geananngel and W.W. Wendlandt, Thermochim. Acta, 113, 383 (1987). 